\title{
Myxobolus absonus sp. n. (Myxozoa: Myxosporea) Parasitizing Pimelodus maculatus (Siluriformes: Pimelodidae), a South American Freshwater Fish
}

\author{
Eduardo F Cellere, Nelson S Cordeiro+ ${ }^{+}$Edson A Adriano
}

\author{
Departamento de Parasitologia, Instituto de Biologia, Universidade Estadual de Campinas, Caixa Postal 6109, \\ 13083-970 Campinas, SP, Brasil
}

A new myxoporean species is described from a freshwater fish in Brazil. Myxobolus absonus sp. n. was found infecting Pimelodus maculatus captured in the river Piracicaba, State of São Paulo, Brazil. Cysts were found free in the opercular cavity. The spores are large (length-15.7 $\pm 1.5 \mu \mathrm{m}$, width-10.2 $\pm 0.7 \mu \mathrm{m}$; mean \pm S.D.) and oval in shape, with the anterior end slightly pointed. The spore valves are relatively thin, smooth, and asymmetrical in a frontal view. The polar capsules are pyriform in shape, and unequal in size; the largest are $6.4 \pm 0.7 \mu \mathrm{m}$ long and $3.6 \pm 0.5 \mu \mathrm{m}$ wide, while the smallest are $4.2 \pm 0.6 \mu \mathrm{m}$ long and $2.5 \pm 0.5 \mu \mathrm{m}$ wide.

Key words: Myxozoa - Myxosporea - Myxobolus absonus sp. n. - Pimelodus maculatus - Brazil - South America

The South American continent, with its numerous rivers, lakes and largest river basin in the world (Amazon basin), has the most diversified fauna of freshwater fish consisting of approximately 8,000 species (24\% of all fish species) (Schaefer 1998). There are also numerous species of marine fishes in the continent's coastal waters. In spite of this variety of fish, only $71(5.7 \%)$ of the more than 1,250 Myxoporea species described to date, have been reported in South America, a small number when compared to other regions of the planet. This low number of South American species probably reflects the general lack of studies in this field. In the last 10 years, 17 species of myxosporeans parasitizing South American fish have been described. In this paper, we describe a new Myxosporea species parasitizing Pimelodus maculatus Lecépède, 1803, a small feral catfish commonly known as "mandi-amarelo". So far, only two Myxosporea species have been reported to parasitize Pimelodus spp.: Henneguya linearis Gurley, 1893, found in Pimelodus sebae and Myxobolus cunhai Penido, 1927, in Pimelodus clarias (Gioia \& Cordeiro 1996).

\section{MATERIALS AND METHODS}

Adult specimens of $P$. maculatus were collected between March 1991 and February 1992 in the river Piracicaba, in the municipality of Piracicaba, State of São Paulo, Brazil. The fishes were preserved on ice and immediately transported to the laboratory for autopsy. Spores were obtained from mature cysts and studied fresh in Lugol's iodine solution (2\%). The India-ink method was used to detect the mucous envelope of the spores. Dry smears were fixed in absolute methanol and stained with Giemsa before examined with an immersion lens. An average of 30 spores were measured using the dimensions recommended by Lom and Arthur (1989). Measurements were taken from fresh spores obtained from frozen fish and were expressed as the means \pm standard deviation ( $\mathrm{S}$.

${ }^{+}$Corresponding author. Fax: +55-19-3788.6282. E-mail: nsilvac@unicamp.br

Received 23 Frebuary

Accepted 16 August 2001
D.). Drawing was done with the aid of a camera lucida. Photomicrographs were obtained using a standard Zeiss microscope and Kodak TMAX 100 film.

\section{RESULTS}

Myxobolus absonus sp. n.

Figs 1-2

Description: spherical whitish plasmodia (cysts) 1-2 mm in size occurred free in the opercular cavity. Spores oval, with the anterior end slightly pointed (Figs 1-2), length$15.7 \pm 1.5 \mu \mathrm{m}$, width $-10.2 \pm 0.7 \mu \mathrm{m} ;$ mean \pm S.D. The spore

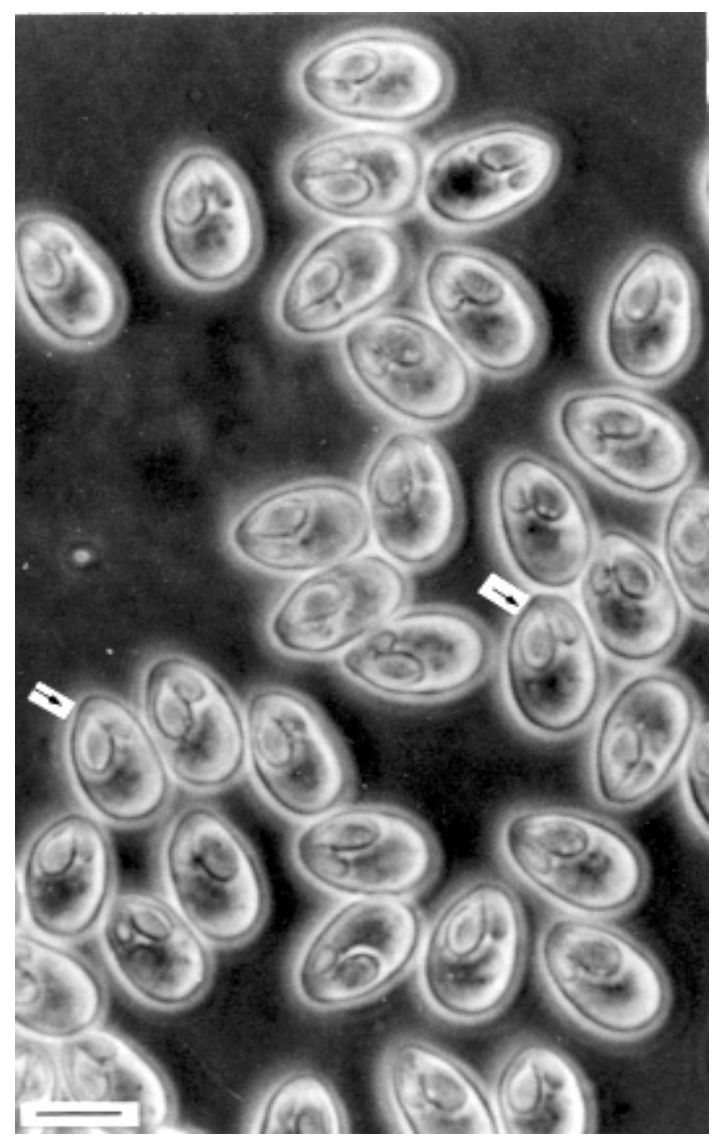

Fig. 1: light microscopic photograph of Myxobolus absonus sp. n. spores in a fresh preparation (phase contrast). Note the unequal size of the polar capsules and curved border of the valve. Bar $=10 \mu \mathrm{m}$ 
valves are thin, smooth and asymmetric in a frontal view (Fig. 1); their sutural end is relatively narrow. The two polar capsules are pyriform in shape, and of unequal size (Figs 1-2), the largest being $6.4 \pm 0.7 \mu \mathrm{m}$ long and $3.6 \pm 0.5$ $\mu \mathrm{m}$ wide and the smallest being $4.2 \pm 0.6 \mu \mathrm{m}$ long and $2.5 \pm$ $0.5 \mu \mathrm{m}$ wide. In lateral view, the polar capsules are in the same plane as the suture line. The polar filament is closely coiled, and aligned perpendicularly to the longitudinal axis of the capsules. In the large capsule, the polar filament has five turns compared to only three in the small capsule. The sporoplasm is large, with two nuclei visible in stained preparations. The iodinophilous vacuole and mucous envelope are absent.

Type host: Pimelodus maculatus Lacépède, 1803 (Siluriformes: Pimelodidae).

Site of infection: opercular cavity (coelozoic parasite). Prevalence: $8.3 \%$ (3 parasitized fishes out of 36 examined). Locality: river Piracicaba, near Piracicaba city, State of São Paulo, Brazil.
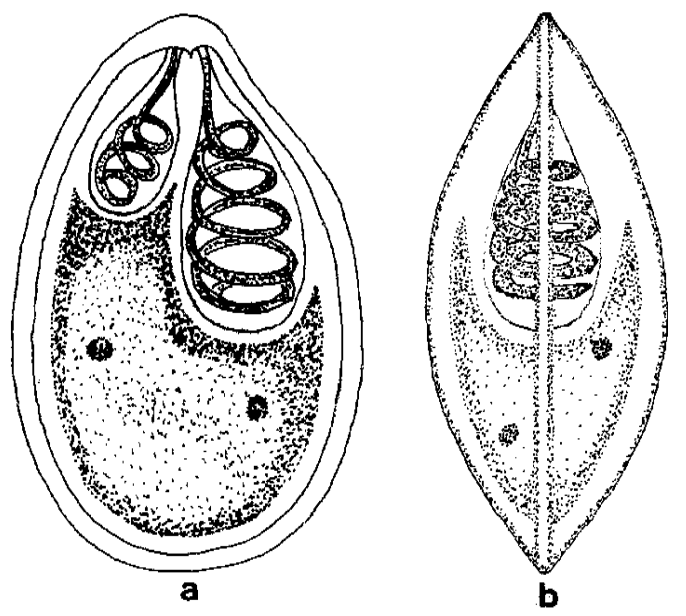

Fig. 2: line-drawing of a mature spore of Myxobolus absonus sp. n. - a: frontal view; b: lateral view. Bar $=10 \mu \mathrm{m}$.
Type material: the slides with stained spores of M. absonus sp. n. (Syntipe) are deposited in the collection of the Museum of Natural History of the Institute of Biology of the State University of Campinas, State of São Paulo, Brazil (accession No.: ZUEC 01; 02; 03).

Etymology: the species name is based on the unequal size of the polar capsules.

\section{DISCUSSION}

Comparison of M. absonus sp. n. with Myxobolus spp. found parasitizing South American and other freshwater fishes shows that the distinctive features in $M$. absonus sp. n. are unequal size of the polar capsules and the asymmetric shape of the valves in frontal view. Of the South American species of Myxobolus, only Myxobolus inaequalis Gurley, 1893 and Myxobolus inaequus Kent and Hoffman, 1948 have polar capsules of unequal size. However, the spores of $M$. inaequalis are much smaller $(5.5 \mu \mathrm{m} \times 3.3 \mu \mathrm{m})$ than in $M$. absonus sp. n., while in $M$. inaequus the spores are larger $(19.8 \mu \mathrm{m} \times 8.6 \mu \mathrm{m})$ than in $M$. absonus sp. n. and more elongated.

Of the Myxobolus spp. from other regions of the world which have spores with polar capsules of unequal size, those of M. bilongi Fomena and Bouix, 1994 have dimensions similar to M. absonus sp. n., but the anterior end of the spores is slightly truncated, and the polar filament of the large polar capsule has 9-10 turns while that of the smaller has 6-7 turns, compared to the 5 and 3 turns, respectively, in M. absonus sp. n.

\section{REFERENCES}

Gioia I, Cordeiro NS 1996. Brazilian myxosporidian's check-list (Myxozoa). Acta Protozool 35: 137-149.

Lom J, Arthur JR 1989. A guideline for the preparation of species descriptions in Myxosporea. J Fish Dis 12: 151-156.

Schaefer SA 1998. Conflict and resolution: impact of new taxa on phylogenetic studies of the Neotropical cascudinhos (Siluroidea: Loricariidae). In LR Malabarba, RE Reis, RP Vari, ZMS Lucena, CAS Lucena (eds), Phylogeny and Classification of Neotropical Fishes, EDIPUCRS, Porto Alegre, p. $375-400$. 